\title{
Periodismo y competencias mediáticas: una aproximación desde contexto colombiano y ecuatoriano
}

\author{
Journalism and media competencies: an approach from a \\ Colombian and Ecuadorian context
}

\author{
Montoya Ramírez, N., Zuluaga Arias, L. y Rivera-Rogel, D. 1 \\ Recibido: 19-09-2019 - Aceptado: 20-01-2020 \\ DOI: https://doi.org/10.26441/RC19.1-2020-A11
}

RESUMEN: Este artículo presenta los resultados de un estudio cuantitativo descriptivo de corte exploratorio realizado en los países de Colombia y Ecuador para evaluar el grado de competencia mediática de 146 periodistas de las ciudades de Medellín (Colombia) y Loja (Ecuador). Se aplicó un cuestionario autoadministrado, estructurado con nueve preguntas sociodemográficas, cuatro sobre las generalidades del nivel de competencia mediática y 24 evaluativas distribuidas en las seis dimensiones de este tipo de competencia con sus respectivos indicadores. Los resultados generales de baja y mediana competencia obtenidos por este grupo de profesionales demanda de intervenciones prioritarias desde trabajos locales, regionales e internacionales que movilicen cooperación científica, académica y política para mejorar el desempeño de una población que debería liderar la formación general de la ciudadanía en competencias mediáticas.

Palabras clave: periodismo; función educativa; competencia mediática; formación del periodista.

ABSTRACT: This article presents the results of a descriptive quantitative exploratory study conducted in the countries of Colombia and Ecuador to assess the degree of media competence of 146 journalists from the cities of Medellín (Colombia) and Loja (Ecuador). A self-administered questionnaire was applied, structured with nine sociodemographic questions, four on the generalities of the level of media competence and 24 evaluative distributed in the six dimensions of this type of competition with their respective indicators. The general results of low and medium-level competition obtained by this group of professionals demand priority interventions from local, regional and international works that mobilize scientific, academic and political cooperation to improve the performance of a population that should lead the general formation of the citizenship in media competitions.

Keywords: journalism; educational role; educational journalism; media competition; journalist training.

\footnotetext{
${ }^{1}$ Nélida Montoya Ramírez es Magíster en Educación y Desarrollo Humano y Docente Investigadora del Programa de Comunicación Social en la Facultad de Comunicación, Publicidad y Diseño de la Universidad Católica Luis Amigó e INEM José Félix de Restrepo (Colombia) nelida.montoyara@amigo.edu.co, https://orcid.org/0000-00024919-8690

Ligia Zuluaga Arias es Magíster en Educación y Desarrollo Humano y Directora del Programa de Comunicación Social en la Facultad de Comunicación, Publicidad y Diseño de la Universidad Católica Luis Amigó (Colombia). ligia.zuluagaar@amigo.edu.co, https://orcid.org/0000-0002-4716-1720

Diana Rivera-Rogel es Doctora en Comunicación y Periodismo por la Universidad Santiago de Compostela, Investigadora del Grupo de Investigación Comunicación, Educación y Tecnología y Directora del Área Sociohumanística de la Universidad Técnica Particular de Loja (Ecuador). derivera@utpl.edu.ec, https://orcid.org/0000-00018476-3635
} 


\section{Introducción}

Podría afirmarse que, en estas realidades saturadas de tecnología y sobreinformación, el periodismo y el periodista han perdido su norte por diversas razones, entre las que pueden destacarse: las dificultades intrínsecas del ejercicio periodístico, las críticas a la calidad y a la veracidad del producto informativo ofrecido actualmente y el abuso del denominado periodismo de fuente (Montoya \& Zuluaga, 2017, pp. 375-376).

Los medios periodísticos se han convertido en "megáfonos" que amplifican información sin sentido, sin confirmación, sin la triangulación de diferentes versiones. Igualmente, el ejercicio del periodismo se ha centralizado en sus funciones informativas y de entretenimiento, que en consecuencia relegan a lo tangencial sus compromisos sociales en los procesos formativos de sus públicos por estar embebidos en una guerra de mercados y en sus intereses políticos, sociales y económicos (Montoya \& Zuluaga, 2014, p.33).

A este panorama se suman las preguntas por la capacidad de lectores, internautas y televidentes de interactuar de manera asertiva y crítica con lo mediático y sus contenidos, por ejemplo, los periodísticos. La apropiación de este universo media-tecnológico y expresivo requiere de un sustrato: las competencias mediáticas y la alfabetización que implican, porque para enfrentar estos consumos culturales hay que desarrollar habilidades que nos permitan discernir "y seleccionar entre una gama muy amplia de oferta formativa e informativa" (Huergo, 2010, p. 75); y para lograrlo se requiere de un proyecto universal (Kendall \& McDougall, 2012) de alfabetización mediática e informacional que genere competencias, que sea digital, multimodal y mediática, pues "nos referimos a una alfabetización crítica, dignificante y liberadora, no a una capacitación como usuario de cualquier nuevo dispositivo que vaya surgiendo" (Gutiérrez \& Tyner, 2012, p. 32).

Y no se está haciendo referencia a una capacitación instrumentalizadora sino al desarrollo de altas capacidades metacognitivas exigidas para afrontar las demandas complejas del ecosistema mediático, es decir, la capacidad de preguntarse los porqués de este ecosistema. Y para ello, la competencia «se construye en cuanto combinación de habilidades cognitivas y prácticas interrelacionadas, conocimiento (incluido el tácito), motivación, valores, actitudes, emociones, y otros componentes sociales y de comportamiento que se movilizan a la vez [...]» (Stiefel, 2010, p. 32) para que los sujetos tengan mayores posibilidades de interacción de manera asertiva con los medios de comunicación. (Montoya \& Zuluaga, 2017, p. 374).

A esta altura, cabe preguntarse: ¿Quién es el responsable social de esta formación en competencias mediáticas? cualquier opción de respuesta debe evitar circunscribirse solo a los escenarios educativos formalizados como la escuela. Estos procesos de formación son una deuda social que deben asumir diferentes actores e instituciones, incluyendo a los medios de comunicación.

Ahora bien, si los medios están llamados a formar en competencias mediáticas, quienes los producen deberían poseer estas competencias en un nivel alto. Y entre este grupo de realizadores, podría suponerse que quienes son formados como periodistas y quienes ejercen el periodismo, de manera connatural, deberían demostrar altos niveles de competencias mediáticas; pero ¿qué pasaría si esto no fuera así?

La investigación que sustenta este artículo evaluó competencias mediáticas entre periodistas de dos ciudades de Colombia y Ecuador y los resultados revelan que las competencias de este grupo profesional están en un nivel medio y bajo. Hallazgos preocupantes, si se tiene en cuenta la importancia de este tipo de competencias dentro del currículum vitae del periodista, como prueba de la preparación de este profesional para desenvolverse en cualquier ámbito como productor y consumidor de medios al interrelacionar conocimientos, aptitudes y actitudes para hacer frente a las exigencias técnicas y expresivas que exige la producción mediática actual; pero al mismo tiempo, para participar como ciudadano del entorno comunicacional y mediático y valorar de manera estética, crítica y ética su propia dieta mediática y su labor como productor de medios. 
Por ejemplo, el mundo digital se transporta a gran velocidad, la información se propaga instantáneamente. Si no se contrasta fuentes y se publica en la plataforma digital al instante, esa información es leída y compartida (Buitrago, Ferrés \& Matilla, 2015). Esta falencia en el campo digital por no estar totalmente instruidos genera el desperdicio del potencial que tiene Internet. William Urrego, Edwin Jiménez y Alfonso Sierra, mencionan que se están desaprovechando oportunidades de innovar la comunicación con base en la tecnología (Cárdenas, 2016).

¿Cómo ejercer, entonces, una profesión de altas responsabilidades sociales cuando el ejercicio de la misma está en crisis y cuándo sus profesionales no pueden demostrar capacidad suficiente en la interacción con los medios que son la esencia de su trabajo profesional? ¿Se pueden producir medios de comunicación desde la falta de competencia como consumidor de los mismos? ¿Qué pasa con la formación de los periodistas y con su desempeño profesional actual?

Estas son sólo algunas de las preguntas que no pueden esquivarse y para las cuáles hay que buscar respuesta en la interrelación del ámbito temático de la competencia mediática con el periodismo; en la revisión de la esencia de la formación de los periodistas; en los retos del ejercicio periodístico en la actualidad y en los abordajes investigativos como los presentados en este manuscrito.

\subsection{Apuntes sobre el estado de la cuestión}

Interrelacionar conceptos como periodismo y competencias mediáticas demanda el esbozo de las principales concepciones y praxis inherentes a estos dos ámbitos temáticos, sumadas al trazado de sus posibilidades de interceptación.

Iniciando con el periodismo, hay que remitirse a sus orígenes porque la revisión de las fundaciones, posibilitan vislumbrar la lógica de los desarrollos históricos y acercarse a la comprensión de las caracterizaciones, funciones, desafíos y hasta de la crisis actual de lo periodístico.

Desde sus orígenes, el periodismo y sus medios de soporte han estado vinculados y determinados por el poder político y económico, por el desarrollo de avances tecnológicos, por sus asociaciones con lo público y la responsabilidad sociocultural de sus praxis. Los albores del periodismo se ubican en los siglos XII y XIII en el Imperio Romano con el propósito de "facilitar la actividad burocrática de los poderes sociales, políticos y religiosos, vía de acceso al pensamiento escrito y, sólo secundariamente, (...) instrumento de la creación intelectual" (Langa, 2010, p.11). Un siglo después, el surgimiento de lo periodístico en Latinoamérica sigue las mismas lógicas europeas.

A partir de del siglo XIX, la prensa transita cuatro etapas: la primera caracterizada por la coexistencia del periodismo ideológico y el periodismo informativo (1870-1920); la segunda destacada por el desplazamiento que el periodismo informativo hace del ideológico (1920); la tercera, que inicia después del final de la Segunda Guerra Mundial, y que marca el comienzo del periodismo moderno, caracterizado por la profundidad y la reflexión en el tratamiento temático (Adaptado de: Alberdi, Armentia, A., Armentia Vizuete, JI., Caminos Marcet, JM. \& Marín Murillo, F., 2003, pp. 277-281). Y, finalmente, la cuarta etapa, fase actual, reconocida por el inicio de una clara y crítica transición entre el periodismo informativo-interpretativo de los últimos años del siglo XX y "unas nuevas formas periodísticas que no tienen todavía un corpus cerrado, pero que se caracterizan por la atención que prestan a nuevas temáticas, nuevas fuentes, nuevos enfoques, nuevas presentaciones y formas de expresión, todo ello orientado a ofrecer un mayor servicio al lector" (Alberdi Ezpeleta et al., 2003, pp. 277-281).

Ahora bien, desde lo histórico para establecer relaciones entre el periodismo y el debate sobre las competencias mediáticas, hay que remitirse a la relación entre educación y medios. Debate epistémico que inicia a mediados del siglo XX, pero que tuvo sus orígenes en las interacciones de lo so- 
cial cultural con los desarrollos tecnológicos, interacción de la cual ha devenido siempre una diada indisoluble y aún vigente: oportunidad y crisis.

A partir de aquí cada artefacto tecnológico y sus procesos de recepción fueron puestos en cuestión. Se ha temido y se teme por el impacto en las audiencias de la fotografía, de la radio y de la televisión. Es en estos medios, y gracias a sus posibilidades técnicas y expresivas, ha florecido el periodismo, razón por la cual, lo periodístico, en su producción y ejercicio, no puede eximirse de la relación de tensión entre las bondades y temores frente a lo mediático. Esto se repite, hoy frente a Internet, pero con mucha mayor complejidad y celeridad por la aparición constante de tecnología con sus propios retos expresivos y por fenómenos digitales como: la convergencia porque Internet incluye el contenido de todos los medios antecesores; la remediación, debido a que los nuevos medios alteran y mejoran los anteriores; estos, entonces, intentan adaptarse a las nuevas realidades y no sucumbir ante lo digital, migran a Internet donde los límites entre medios son difusos, por ejemplo, la radio en lo digital ya se nutre de la imagen y la transmediación, “...Un tipo de relato donde la historia se despliega a través de múltiples medios y plataformas de comunicación, y en el cual una parte de los consumidores asume un rol activo en ese proceso de expansión" (Scolari, 2013, p.46).

Como seres sociales, las interacciones comunicativas han sido esenciales en nuestra evolución. Esta necesidad comunicativa nos ha abocado a generar diferentes códigos y artefactos tecnológicos que le han dado soporte y que derivaron en el requerimiento de su asimilación, proceso al que se le ha conocido como alfabetización y que en un inicio fue prácticamente sinónimo de adquisición de la competencia escritural. Sin embargo, en su historia hay otras etapas, además de esta primera.

Una segunda, la de la alfabetización audiovisual asociada a medios como el cine y la televisión; una tercera que es la alfabetización digital, propia de finales del siglo XX y de este siglo XXI, la cual exige un lenguaje informático $\mathrm{y}$, podría finalmente hablarse, de que hoy estamos trasegando otra nueva etapa en la que se requiere la alfabetización informativa y mediática. Esta es requerida por la convergencia de medios: todos confluyen con sus riquezas expresivas en un mismo soporte, el digital, y en correlación esta alfabetización abarca a todas las anteriores e implica exigencias adicionales por el nuevo contexto intelectual semiótico y comunicativo (N.M, Montoya, comunicación personal-tesis doctoral en proceso de elaboración, 5 de enero, 2020). A esta compleja urdimbre debe adicionársele la deuda social frente a todas las alfabetizaciones que se han planteado aquí, porque todas han sido puestas en cuestión y no han alcanzado una implementación completa, sobre todo, aquellas no tradicionales.

Hablar de alfabetización en relación con los medios de comunicación deriva en plantear ¿sobre qué competencias alfabetizar? Y si bien de alfabetización mediática se ha discutido desde mediados del siglo pasado, solo en las últimas cuatro décadas ha irrumpido en el término competencia mediática. Vale dejar en claro, que ambos vocablos, alfabetización y competencia, han estado acompañados de una diversidad de términos: audiovisual, multimedia, digital, informacional, mediática, entre otras; y si bien, todavía no hay consenso sobre una acepción definida y cohesionada, este manuscrito opta por alfabetización mediática y competencia mediática, porque se consideran términos supraordinados de los anteriores y en consonancia con los fenómenos comunicacionales, antes mencionados, de la convergencia, la remediación y la hipermediación.

A esta altura cabe aproximarse a la concepción sobre la competencia mediática "no solamente como el desarrollo de la capacidad humana de recibir y producir información, sino como un entramado en el que intervienen y se cruzan los campos de la comunicación, la educación y la cultura" (Manrique-Grisales, et alt., 2017, p.9).

El concepto de competencia nació asociado al mundo laboral, al mundo de la empresa. Gradualmente se fue integrando en el mundo académico, hasta convertirse en el eje conceptual de las reformas 
educativas en la mayor parte de los países [...] Se suele entender por competencia una combinación de conocimientos, destrezas y actitudes que se consideran necesarios para un determinado contexto (Ferrés \& Piscitelli, 2012, p.76).

Con el ánimo de enriquecer el término de competencia mediática y validarlo para el entorno latinoamericano, debe tenerse en cuenta que:

La configuración social, originada en los cambios en la circulación de los saberes, está re-creando un tipo de competencias culturales y cognitivas que no parecen apuntar en el sentido de las competencias para la generación de rentabilidad y competitividad [...] (Barbero, 2003, p.17).

[...] La concepción primera de competencia en la educación está asociada a la idea de destreza intelectual, habilidad que se asocia a la de innovación, y por tanto a la creatividad. (p. 23).

En una propuesta de alfabetización o de educación mediática se debe partir de reconocer el origen más cognitivo, cultural y comunicativo de las competencias mediáticas, más que el empresarial. Las competencias mediáticas deben potenciar la excelencia personal y "ha de contribuir a desarrollar la autonomía [...] de los ciudadanos y ciudadanas, así como su compromiso social y cultural" (Ferrés \& Piscitelli, 2012, p.76).

Asimismo, las competencias mediáticas deben ser una mixtura de conocimientos, destrezas, valores y actitudes multifuncionales y transferibles para un determinado contexto que la ciudadanía necesita adquirir. Estas competencias estarían insertas en un entorno digital y de consumo mediático de ocio y tiempo libre (Sánchez \& Contreras, 2012, p.28) y le sirven a una persona para desenvolverse en un contexto social y cultural específico en distintas dimensiones.

El término dimensiones, centra la atención en entender que desarrollar la competencia mediática requiere del perfeccionamiento de diferentes esferas con sus respectivos indicadores y ámbitos. Al respecto, el desarrollo de las investigaciones que nutren este artículo se basaron en la propuesta de dimensiones e indicadores de competencia mediática de Joan Ferrés y Alejandro Piscitelli (2012).

El modelo propuesto por Ferrés y Piscitelli (2012) es genérico y flexible y en él cada dimensión se agrupa en dos ámbitos: el del análisis y el de la expresión, cada uno de ellos expresa unos indicadores en términos de capacidades, conocimientos, habilidades y actitudes, que debe demostrar el sujeto competente en comunicación mediática (Manrique-Grisales, et al., 2017, p.9), también hay que considerar que al evaluar a partir de este modelo se debe considerar lo holístico porque ni las dimensiones ni sus ámbitos ni sus indicadores pueden [...] explicarse si no es en interacción con todas las demás. Pero la comprensión global del fenómeno exige especificar y diferenciar cada una de las magnitudes relevantes para no pasar por alto ninguna de ellas ni en el análisis ni en la praxis expresiva (Ferrés \& Piscitelli, 2012, p.77). La tabla 1. sintetiza este modelo.

Las competencias mediáticas y la alfabetización que implican han determinado a lo largo de la historia los procesos civilizatorios y, en buena medida, los desarrollos culturales, las formas de organización, y la distribución de poderes en la sociedad (Pérez \& Varis, 2012, p. 52). Por ello, es necesario resaltar aquí la importancia de estas competencias para todo sujeto consumidor de medios; pero en especial, señalar que esta relevancia aumenta frente a sujetos sociales como los periodistas, quienes son a la vez consumidores de medios y uno de los responsables formales de la producción que por estos canales circula. 
Tabla 1. Dimensiones, ámbitos e indicadores de la competencia mediática

\begin{tabular}{|c|c|c|}
\hline \multirow{2}{*}{ Dimensiones } & \multicolumn{2}{|l|}{ Indicadores } \\
\hline & Ejemplos ámbito de análisis & Ejemplos ámbito de expresión \\
\hline Lenguaje & $\begin{array}{l}\text { (4 Capacidades y } 1 \text { habilidad) } \\
\text { Capacidad de: } \\
\text { *Interpretar analizar y valorar los diversos códigos, } \\
\text { de representación y los mensajes desde la } \\
\text { perspectiva del significado y del sentido, de las } \\
\text { estructuras narrativas y de las convenciones de } \\
\text { género y de formato. } \\
{ }^{*} \text { Comprender historias de múltiples medios, } \\
\text { soportes, plataformas y modos de expresión } \\
\text { para establecer relaciones de intertextualidad y } \\
\text { elaborar conocimientos abiertos, sistematizados e } \\
\text { interrelacionados. }\end{array}$ & $\begin{array}{l}\text { (3 Capacidades) } \\
\text { Capacidad de: } \\
\text { *Expresarse mediante una amplia gama de } \\
\text { sistemas de representación y de significación. } \\
\text {-Elegir entre distintos sistemas de representación y } \\
\text { distintos estilos en función de la situación } \\
\text { Comunicativa, del tipo de contenido que hay que } \\
\text { Transmitir y del tipo de interlocutor. }\end{array}$ \\
\hline Tecnología & $\begin{array}{l}\text { (3 Capacidades y } 1 \text { habilidad) } \\
\text { *Comprensión del papel y efectos que desempeñan } \\
\text { en la sociedad las tic. } \\
\text { *Habilidad para interactuar de manera significativa } \\
\text { Con medios. }\end{array}$ & $\begin{array}{l}\text { (3 Capacidades) } \\
\text { Capacidad de: } \\
\text { *Manejar con corrección herramientas } \\
\text { Comunicativas en un entorno multimedial } \\
\text { y multimodal adecuándolas a objetivos } \\
\text { comunicativos. } \\
\text { • Elaborar y manipular imágenes y sonidos } \\
\text { desde la conciencia de cómo se construyen las } \\
\text { representaciones de la realidad. }\end{array}$ \\
\hline $\begin{array}{l}\text { Recepción e } \\
\text { interacción }\end{array}$ & $\begin{array}{l}\text { (6 Capacidades y } 2 \text { conocimientos) } \\
\text { *Capacidad de selección, de revisión y de } \\
\text { autoevaluación de la propia dieta mediática, en } \\
\text { función de unos criterios conscientes y razonables. } \\
{ }^{*} \text { Conocimiento de la importancia del contexto en } \\
\text { Los procesos de interacción. }\end{array}$ & $\begin{array}{l}\text { (2 Capacidades y } 1 \text { conocimiento y } 1 \text { actitud) } \\
{ }^{\star} \text { Capacidad de llevar a cabo un trabajo colaborativo } \\
\text { mediante la conectividad y la creación de } \\
\text { plataformas que facilitan las redes sociales. } \\
{ }^{\star} \text { Actitud activa en la interacción con las pantallas, } \\
\text { Entendidas como oportunidad para construir una } \\
\text { ciudadanía más plena, un desarrollo integral, para } \\
\text { transformarse y para transformar el entorno. }\end{array}$ \\
\hline $\begin{array}{l}\text { Procesos de } \\
\text { producción y } \\
\text { difusión }\end{array}$ & $\begin{array}{l}\text { (4 Conocimientos) } \\
\text { Conocimiento de: } \\
\text { *Las diferencias básicas entre las producciones } \\
\text { individuales y las colectivas, entre las populares y } \\
\text { las corporativas, y, en el ámbito de estas últimas, si } \\
\text { es el caso, entre las elaboradas por instancias de } \\
\text { titularidad pública y privada. } \\
\text { *Los factores que convierten las } \\
\text { Producciones corporativas en mensajes sometidos } \\
\text { a los condicionamientos socioeconómicos de toda } \\
\text { industria. }\end{array}$ & $\begin{array}{l}\text { (6 Capacidades y } 1 \text { conocimiento) } \\
{ }^{*} \text { Capacidad de trabajar, de manera colaborativa, } \\
\text { en la elaboración de productos multimedia o } \\
\text { multimodales. } \\
{ }^{*} \text { Conocimiento de las fases de los procesos de } \\
\text { producción y de la infraestructura necesaria para } \\
\text { producciones de carácter personal, grupal o } \\
\text { corporativo. }\end{array}$ \\
\hline $\begin{array}{l}\text { Ideología y } \\
\text { valores }\end{array}$ & $\begin{array}{l}\text { (7 Capacidades y } 1 \text { habilidad y } 1 \text { actitud) } \\
\text { *Capacidad de descubrir la manera en que las re - } \\
\text { Presentaciones mediáticas estructuran nuestra } \\
\text { percepción de la realidad, a menudo mediante } \\
\text { comunicaciones inadvertidas. } \\
\text { *Habilidad para buscar, organizar, contrastar, } \\
\text { priorizar y sintetizar informaciones procedentes de } \\
\text { distintos sistemas y de diferentes entornos. } \\
{ }^{*} \text { Actitud ética a la hora de descargar productos } \\
\text { Útiles para la consulta, la documentación o el } \\
\text { visionado de entretenimiento. }\end{array}$ & $\begin{array}{l}\text { (3 Capacidades) } \\
\text { *Aprovechar las nuevas herramientas } \\
\text { Comunicativas para transmitir valores y para } \\
\text { contribuir a la mejora del entorno, desde una actitud } \\
\text { de compromiso social y cultural. } \\
\text { ^Elaborar productos y de modificar los existentes } \\
\text { para cuestionar valores o estereotipos presentes en } \\
\text { algunas producciones mediáticas. }\end{array}$ \\
\hline Estética & $\begin{array}{l}\text { (3 Capacidades y } 1 \text { habilidad) } \\
{ }^{*} \text { Capacidad de extraer placer de los aspectos } \\
\text { formales, es decir, no solo de lo que se comunica } \\
\text { sino también de la manera cómo se comunica. } \\
{ }^{\star} \text { Sensibilidad para reconocer una producción } \\
\text { Mediática que no se adecue a unas exigencias } \\
\text { mínimas de calidad estética. }\end{array}$ & $\begin{array}{l}\text { (2 Capacidades) } \\
{ }^{\star} \text { Capacidad de producir mensajes elementales } \\
\text { Que sean comprensibles y que contribuyan a } \\
\text { incrementar los niveles personales o colectivos de } \\
\text { creatividad originalidad y sensibilidad. }\end{array}$ \\
\hline
\end{tabular}

Fuente: Elaboración propia con información de Ferrés \& Piscitelli (2012). 
A lo anterior se suma, una realidad periodística actual que evidencia crisis, lo cual está sugiriendo la necesidad de cambios en las praxis profesionales y en los procesos sociales que explican y ayudan a interpretar hoy a la prensa. Entre las causas relacionadas con esta crisis, destacamos: el desaprovechamiento por quienes producen medios o son periodistas, tal vez por falta de competencia, de las ventajas de conectividad, accesibilidad, ubicuidad y usabilidad de un entorno digital que se impone inexorablemente frente a los medios tradicionales; las dificultades de orden económico como "la descapitalización mediática que provoca cambios en las estructuras de propiedad de los principales grupos, cierres o reestructuración de las unidades menos rentables" (Campos, 2010, p.20) y la puesta en duda de las prácticas y del ejercicio del periodismo por factores como: la criticada visión mercantilista que se debate entre la tensión: dinero o a la verdad; el abuso del denominado 'periodismo de fuente' que ha convertido a los periodistas en copistas de notas ajenas y la falta de reflexión sobre temas que deberían permear la práctica profesional como la ética, la finalidad social de los medios, la responsabilidad social y servicio público.

Esta realidad dificulta más el ejercicio del periodismo y deja entrever, por los menos, tres consideraciones que complejizan este ejercicio profesional y que deben motivar procesos de resignificación en torno a lo periodístico

La primera, la necesidad de un periodismo que asuma las tendencias actuales de las funciones de los medios, las cuales incluyen lo educativo. "En efecto, se habla de la función informativa y de la interpretación de la realidad, aspectos básicos en la actividad periodística, cuya esencia radica precisamente ahí. También se debate sobre la capacidad para conferir estatus y reforzar determinadas normas sociales [...]" (Gómez, 2017, p.50) y la función de transmitir contenidos culturales o función educativa, con mayores retos en la actualidad debido al ecosistema hipertecnológico y comunicativo.

...una reflexión sistemática sobre los aspectos educadores de la información de actualidad, coadyuvante necesario de una orientación social contemporánea y determinante que llamamos Sociedad Educativa o Educación para Toda la Vida [...] El periodista hace periodismo educativo, por tanto, cuando contempla la actualidad teniendo en cuenta el beneficio de los públicos: hacerles descubrir o reforzar sus posibilidades personales de participar responsablemente en la vida social. Cuando informa, puede contribuir a formar un hombre capaz de elevarse al nivel de la civilización moderna, o sea, de encontrar el sentido de la vida en este nuevo mundo (Raigón Pérez de la Concha, 1998).

La segunda consideración es resignificar la relevancia de la prensa y lo periodístico en lo social de hoy:

...se reconoce a la prensa como dinamizadora cultural; como formadora y representadora de la realidad; como generadora de conocimiento autoridad y legitimación política y ciudadana. Y aunque se contempla como medio de difusión, como dispositivo tecnológico, como empresas mercantil e instrumento de control y moldeamiento social (Orozco, 1997, p. 27); se tiene claro que debe lograrse un equilibrio entre estos tipos de intencionalidades para que pueda ser transversalizada por lo educomunicativo (Montoya \& Zuluaga, 2017, p. 376).

Y la tercera, revisar la formación de los periodistas para que su perfil sea coherente con los retos que impone el siglo XXI. Esto implica entre otros asuntos:

...retomar los principios del periodismo de calidad que deben ser inalterables porque la nueva tecnología ha hecho tanto ruido, ha metido tanta presión, que mientras se discute de modelos de negocios y apuestas por web o papel se han perdido elementales actitudes de indagación, comprobación y buen uso del lenguaje. Y también de crítica, sobre las propias actitudes, y sobre las ajenas (Cebrián, 2015, p. 26).

Igualmente, al ganar terreno el periodismo como espectáculo ha perdido de vista la información periodística rigurosa, la separación clásica y oportuna de información y opinión, hechos que se hace apremiante corregir. 
En las sociedades democráticas actuales un periodista no puede ser

...un profesional "sin más", como señala Gil (1999). "Su actividad informativa tiene una trascendencia social reconocida y explicitada en el reconocimiento de derechos como la cláusula de conciencia y el secreto profesional. El respeto a estos derechos de los periodistas, la independencia de los medios y la pluralidad informativa constituyen uno de los pilares fundamentales del Estado de Derecho" (Gómez, 2017, p. 53).

En esta línea, la misión del ejercicio social del periodista, además de informativa, debe ser orientadora y educadora (Gómez, 2017, p. 51). Y acercarse a estos terrenos que algunos consideran, erróneamente, exclusivos del sector educativo implica una preparación exigente.

"Formar para esta profesión requiere, pues, del manejo de muchos mimbres para realizar el cesto. El periodismo es una actividad multidisciplinar, mitad profesión por su indudable ámbito intelectual, mitad oficio por lo que tiene del uso de herramientas" (Cebrián, 2015, p. 28). Estas últimas son un medio que alcanza valor, desde cimientos profesionales que le den al aprendiz un conocimiento suficiente de ética, derecho, historia, sociología, idioma, lengua, entre otros; pero que igualmente se actualice en debates más recientes como: la articulación necesaria entre lo mediatecnológico y lo educativo y la responsabilidad del entorno periodístico en la formación de la ciudadanía en competencias mediáticas (Cebrián, 2015, p. 28).

Cuando el periodista filtra de manera interpretativa la realidad y selecciona los hechos sociales que son relevantes para el lector, esta síntesis de información y cultura, adquiere ilimitadas posibilidades educativas, con capacidad para desarrollar en el ciudadano un pensamiento crítico capaz de entender y dominar las claves sociales, políticas, culturales, económicas... Y con la posibilidad de contribuir creativamente en la construcción de nuevos modelos sociales.

Para promover la criticidad se debe ser crítico, por esta razón aquellos grupos sociales, que como los periodistas, deberían liderar la formación general de la ciudadanía en competencias para interaccionar con los medios de comunicación, estarían obligados, a su vez, a ser competentes al respecto.

Sin competencias mediáticas y la alfabetización que implican ¿cómo enfrentar estos consumos culturales? Hay que desarrollar habilidades cognitivas para interactuar con estos bienes culturales, aprender a discernir "y seleccionar entre una gama muy amplia de oferta formativa e informativa" (Huergo, 2010, p. 75).

No se trata solo del manejo de los artefactos tecnológicos, hay que desarrollar capacidades metacognitivas altas para enfrentar las complejas demandas del actual ecosistema mediático, o sea, poder preguntarse por los porqués de este ecosistema. Y para ello, la competencia "se construye en cuanto combinación de habilidades cognitivas y prácticas interrelacionadas, conocimiento (incluido el tácito), motivación, valores, actitudes, emociones, y otros componentes sociales y de comportamiento que se movilizan a la vez para llevar a cabo una acción efectiva" (Stiefel, 2010, p 32).

Quienes han aceptado el compromiso social y ciudadano de desempeñarse como periodistas no tienen excusas, por eso es necesario que adquieran una formación en competencias mediáticas.

Esto implica la adquisición de actitudes, habilidades y conocimientos de alto nivel en torno a las seis dimensiones que estructuran este tipo de competencia: Lenguaje, con la especificidad expresiva según el medio; Tecnología, referida al manejo técnico-operativo de la herramienta; Procesos de Interacción con medios, que exige participar en el ecosistema comunicacional-mediático; Procesos de Producción y Difusión, la ciudadanía en general debe estar en capacidad de expresarse con cualquiera de las herramientas actuales; Ideología y Valores, implica la selección crítica y asertiva del 
consumo mediático y la Estética que demanda el conocimiento de valores artísticos para la producción de medios y las capacidades sensibles que ellos activan. Cada una de estas dimensiones deben fortalecerse y trabajarse en torno a dos ámbitos: el de la producción de mensajes propios y el de la interacción con mensajes ajenos (Ferrés \& Piscitelli, 2012, p. 75).

Podría plantearse como hipótesis que trabajar en medios y producir contenidos, otorga a los periodistas competencia mediática. Sin embargo, la investigación que sustenta este artículo, devela que esto no es tan simple y para explicarlo, a continuación esbozamos la ruta que permite plantear este tipo de aseveraciones.

\subsection{Contexto investigativo}

El proceso de investigación que da origen a este manuscrito hace parte de estudios locales e internacionales más amplios. Tanto en Colombia, específicamente en la ciudad de Medellín, como en Ecuador, en ciudades como Zamora y Loja, se han realizado evaluaciones del grado de competencia mediática en diferentes ámbitos sociales, uno de ellos, el de los profesionales de la comunicación que ejercen como periodistas.

Estos estudios latinoamericanos, han tomado como punto de referencia investigaciones iberomericanas y grupos científico-académicos que han contribuido a la consolidación del ámbito de la competencia mediática. En España las investigaciones: El grado de Competencia Mediática en la Ciudadanía Andaluza (2006) y la I+D, Competencia mediática en un entorno digital. Diagnóstico de necesidades en tres ámbitos sociales, de referencia: los profesionales de la comunicación, los profesionales de la enseñanza obligatoria y los formadores universitarios tanto en el área de la comunicación (Comunicación Audiovisual, Periodismo y Publicidad) como en el de la educación (2011-2017); en Colombia: Competencia Mediática en colegios públicos del Valle del Cauca (2013-2014) y Evaluación del grado de competencia mediática en tres ámbitos sociales de la ciudad de Medellín (2015-2017) y en Ecuador: Nivel de competencias relacionado a la educación en medios de comunicación, que tienen estudiantes y profesores del país (2016). Entre los grupos científico-académicos están: G.I. Ágora, Grupo de Estudios e Investigaciones Educativas en Tecnologías de la Comunicación, Orientación e Intervención Sociocultural de la Universidad de Huelva; el Grupo Comunicar: Colectivo Andaluz de Educación y Comunicación y la Red Interuniversitaria Euroamericana de Investigación sobre competencias mediáticas, Alfamed, que reúne a más de 200 investigadores de 16 países euroamericanos, y de la que hacen parte las autoras de este artículo.

Cuando se revisa la producción científica en relación con la evaluación del grado de competencia mediática, se halla que esta se ha centrado más sobre la ciudadanía en general, pero frente al colectivo de periodistas ha sido más limitada y centralizada o en sus percepciones sobre el término competencia mediática; en los procesos formativos de los profesionales de la comunicación frente a este tipo de competencias o relacionadas con la formación general del periodista o con la relacionada con el ecosistema digital actual, pero que no hace alusión directa a la competencia mediática: Ejemplos:

La educación en competencia mediática en el CV de los periodistas (Buitrago, Ferrés \& García, 2015), este estudio español partió de la pregunta: ¿Cómo perciben la Educación en competencia mediática los profesionales de la comunicación?, plantea en sus conclusiones que:

...la mayoría de los profesionales ven necesaria la competencia mediática $(\mathrm{CM})$, tanto dentro del currículo universitario como para su actualización en el contexto digital. La Educación en CM no ha podido desarrollarse hasta ahora en todo su potencial pues durante décadas no han existido las herramientas necesarias como para generalizar su implantación. El actual contexto digital representa un mundo lleno 
de oportunidades para la formación y para la actualización de conocimientos (Buitrago, Ferrés \& García, 2015, p.118).

La educación mediática, una asignatura pendiente en la formación de periodistas, publicitarios y comunicadores audiovisuales (Tucho, Fernández-Planells, Lozano \& Figueras-Maz, 2015), estudio que analizó el contenido de asignaturas directamente relacionadas con la Educación Mediática de aproximadamente 117 programas profesionales y que reveló que son escasas las materias específicas sobre educación mediática y que sus contenidos se vinculan prioritariamente con el ámbito de la ideología y valores en detrimento de otras dimensiones de este tipo de competencias como la estética o los procesos de interacción (Tucho, et al., 2015, p. 689); Además, se concluye que la incidencia de la educación mediática en los estudios de comunicación en España tiene un carácter irregular y fragmentario.

Consumo informativo y competencias digitales de estudiantes de periodismo de Colombia, Perú y Venezuela (Romero \& Aguaded, 2016); estudio con una muestra de 1.603 estudiantes de tercer año en universidades privadas de Medellín, Lima y Caracas, que revela como ante el consumo informativo las competencias mediáticas han sido adquiridas, predominantemente, de forma autodidacta.

El periodista frente a los nuevos retos y escenarios de la convergencia mediática en Colombia (Zambrano, García \& Barrios, 2019, pp- 587-607). La investigación encuestó 193 personas entre estudiantes, egresados, docentes, decanos y directores de programa, además, revisó planes de estudios programas de Comunicación y Periodismo, competencias, perfiles profesionales y tendencias para constatar si incluyen la convergencia mediática (42 programas de Europa, 17 de América y 57 de Colombia de 92 que existen en este país). Entre los resultados se destaca que los:

...programas de Comunicación y Periodismo de Europa, América y Colombia, en la mayoría no apropian la comunicación digital, la producción de contenidos, lenguajes, narrativas, multimedia, redes, formatos informativos e interactivos y nuevos géneros periodísticos, según las preferencias de los medios y la audiencia. Se basan en el diseño de productos, estrategias comunicativas, elaboración de diagnósticos, modelos comunicativos organizacionales, educativos y sociales (Zambrano, et al., 2019, p. 595).

Y finalmente, se destaca la investigación: Limitantes Formativas en la praxis profesional: estudio de la situación de periodistas en Chile, México, Ecuador y Colombia (Gutiérrez, Domínguez, Odriozola \& Ferreira, 2017). Estudio internacional que buscó determinar la percepción sobre la formación universitaria y el nivel de satisfacción con dicho proceso, entre periodistas en ejercicio de Chile, México, Ecuador y Colombia. Está investigación develó falencias frente a las bases tradicionales de la formación de estos profesionales; deja entrever dificultades en relación con los nuevos escenarios comunicacionales y tecnológicos y, adicionalmente, no hace ninguna alusión explícita a la necesidad de la competencia mediática.

A todo los anterior se suma un ejercicio profesional en ambos países, Colombia y Ecuador, que suma crisis a las crisis generales que ya se han planteado. La siguiente tabla comparativa realiza una síntesis de las principales circunstancias que han determinado las prácticas profesionales en ambos territorios en el período 2007 a 2019. 
Tabla 2. Comparativo entre el ejercicio profesional periodístico en Colombia y Ecuador

\begin{tabular}{|c|}
\hline La relación medios \\
\hline $\begin{array}{l}\text { *Desde el 2007, en la presidencia han estado gobiernos de } \\
\text { derecha. }\end{array}$ \\
\hline $\begin{array}{l}\text { `El gobierno y medios de comunicación trabajan como alia- } \\
\text { dos de una hegemonía política basada sociedad de merca- } \\
\text { do y privilegio para los más ricos. }\end{array}$ \\
\hline $\begin{array}{l}\text { * En colombia, a diferencia de ecuador no existen leyes } \\
\text { específicas sobre regulación de medios de comunicación. } \\
\text { Porque desde la jurisprudencia se tiene claro que no habría } \\
\text { objetividad si es el poder público el que controla los medios. } \\
\text { Carecería de cualquier objetividad el que sea el poder públi- } \\
\text { co quien controle los medios. Hay justificaciones y senten- } \\
\text { cias desde la corte constitucional que protegen la libertad } \\
\text { de expresión. Sin embargo, a mediados de } 2019 \text { se aprobó } \\
\text { en la cámara y en el senado la ley de modernización de } \\
\text { las tecnología de la información y las comunicaciones (tic), } \\
\text { que a pesar de sus bondades ha sido cuestionada porque } \\
\text { atenta contra la autonomía en la producción de contenidos y } \\
\text { no estimula la producción nacional y la convergencia de los } \\
\text { servicios audiovisuales. }\end{array}$ \\
\hline
\end{tabular}

. *Asignaciones de canales privados se han usado como instrumento de control de agenda mediática,

*El gobierno persigue e intimida a periodistas y medios de comunicación que buscan ser críticos a su labor. Y aunque el periodismo independiente ha denunciado grandes escándalos políticos, ha tenido poco impacto ciudadano de los medios.

\section{Ecuador}

${ }^{*}$ A diferencia de colombia, desde el 2007 y has-

ta el 2017 este país estuvo bajo el mando del mismo presidente. A partir del 2017 es relevado, pero ambos dirigentes pueden considerarse de los autodenominados gobiernos de izquierda progresista o la nueva izquierda latinoamericana, que han gobernado américa latina en esta última década, evidencian que los gobiernos necesitan de los medios para gobernar.

* Por lo menos, en el período el 2007-2017, y a diferencia de colombia, en ecuador el gobierno escogió a los periodistas y a los medios como la oposición política y los periodistas se creyeron políticos.

* Desde el 2013 fue establecida la ley orgánica de comunicación. Ley que desde su propuesta inicial generó conflictos porque a pesar de sus iniciativas como las medidas antimonopolio; la prohibición de que los dueños de bancos sean también dueños de medios; la figura de la responsabilidad ulterior respecto de las consecuencias sociales de los mensajes mediáticos; la distribución equitativa de frecuencias entre medios públicos, privados y comunitarios; también entraña un sistema integral de control de la esfera pública basado en la alta propaganda, la creación de medios públicos y la contundencia comunicativa del presidente. Debe acotarse que en el 2018 esta ley tuvo reformas. Como por ejemplo que la libertad de expresión ya no es un servicio público, sino que toda persona tiene el derecho a la libertad de pensamiento y expresión.

* El estado es el mayor empleador de periodistas cuyas ofertas laborales llamativas están distribuidas en los 21 medios de comunicación que maneja el estado, directa o indirectamente.

\begin{tabular}{l} 
Colombia \\
\hline *Durante años colombia fue el país con más periodistas \\
muertos, exiliados o amenazados por razones del conflicto \\
armado, las mafias y la política, lo que restringió la libertad \\
de prensa. Y si bien en la actualidad esta problemática ha \\
disminuido, sigue siendo un peligro vigente. Los asesinatos \\
de periodistas se mantienen en la impunidad con respecto a \\
los autores intelectuales en casi el $100 \%$ de los casos. \\
\hline *Dos grupos económicos son dueños de casi la totalidad de \\
la audiencia mediática.
\end{tabular}

la audiencia mediática.
*Existe conexión entre los principales medios privados y los grupos económicos. Esta alta concentración monopólica pretendió ser diluida con la puesta en marcha de la ley orgánica de comunicación y con la creación de más de una docena de medios públicos que compiten por una audiencia cuyas posibilidades de conexión a la red van en aumento. 


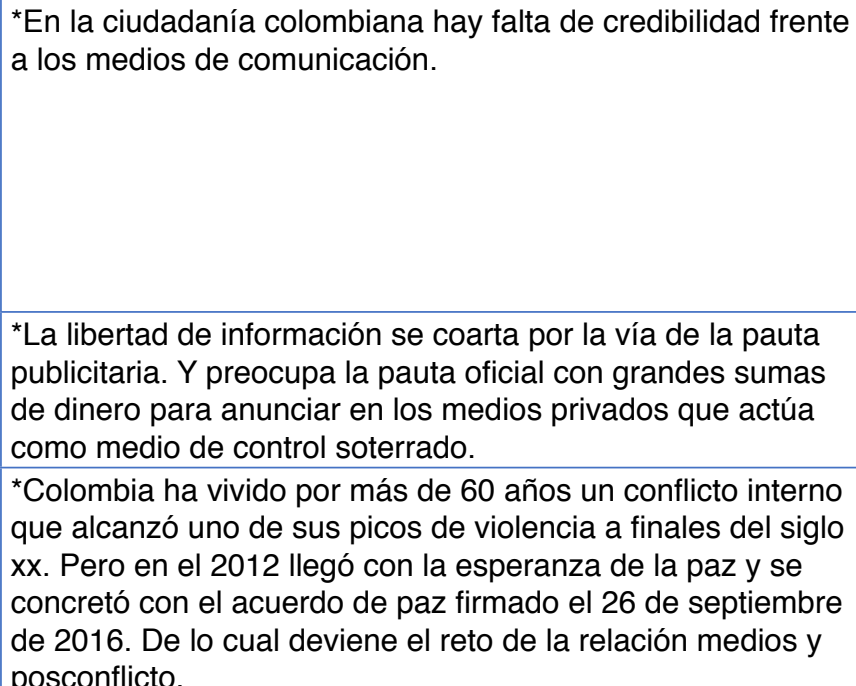
* La ciudadanía ecuatoriana ha sido crítica frente a los medios de comunicación. Y al igual que en colombia los medios pierden credibilidad por su participación directa en política, por ser defensores del statu quo y de los valores del sistema dominante lo cual ha profundizado el divorcio entre la realidad social y la realidad expuesta por los medios.

*Los medios son coartados porque la mayoría son controlados de manera directa por el estado

* En ecuador el reto es superar que, en la confrontación directa con lo gubernamental, los periodistas aceptaron pelear en el terreno del adversario, es decir, en el campo de la política en lugar de hacerlo desde el campo del periodismo y la información.

\section{Periodistas y periodismo}

Colombia

Ecuador

*Aunque no se puede generalizar en colombia, como en muchos países, los periodistas, se han convertido en borregos, ante las presiones de hacer parte de unidades de negocios en donde priman el cálculo económico y político por encima de la calidad de la información.

*La prensa escrita tradicional está en franca decadencia, en particular los diarios, que pierden lectores y pauta de manera acelerada.

Aunque hay radio y televisión comunitaria, en la actualidad los medios públicos se circunscriben a tres, con tres apoyos adicionales en web. Medios de bajo impacto y con poca difusión.

En una investigación reciente, los periodistas colombianos entrevistados manifestaron no encontrar una relación entre lo aprendido en su formación universitaria y el ejercicio laboral: sus temas, problemáticas y contextos. "También señalan que se vive una tensión entre quienes ejercen, pero han estudiado alguna otra carrera y quienes lo ejercen desde la política" (gutiérrez \& et al, 2017). Asimismo, se cuestiona la falta de preparación, por ejemplo, en relación con internet.

Fuente: Elaboración propia con base en Rincón, O. (2010): ¿Por qué nos odian tanto? [Estado y medios de comunicación en América Latina]. Bogotá, Colombia: Centro de Competencia en Comunicación para América Latina. Recuperado de: https://goo.gl/dZ5kC7 y Gutiérrez Atala, F., Domínguez Panamá, J., Odriozola Chné, J. \& Ferreira Jiménez, J. (2017). Limitantes Formativas en la praxis profesional: estudio de la situación de periodistas en Chile, México, Ecuador y Colombia.Comuni@cción, 8 (1). 
$\mathrm{Al}$ anterior contexto hay que sumarle, una realidad de la que no se puede escindir ningún país: hacer parte de una realidad hiperconectada y digitalizada. Los grandes medios son concientes de esto, han migrado a estos entornos, pero todavía están lejos de entender las exigencias de este ecosistema comunicacional y los modos de informar en él.

En esta trama "El periodismo no [puede ser] un oficio muerto porque sus ganas de molestar a los poderes y su función de narrador social de la democracia siguen intactas; solo que hay que hacerlo de otro modo" (Rincón, 2017, p. 23). El periodismo debe recuperar el contexto, volver a los datos, analizar qué nos está pasando como países y sociedad, pausar lo que sucede en lo digital, alejarse de los "me gusta" y generar criterio sin importar el canal (Rincón, 2017, p. 23).

El periodismo debe resignificarse y parte de estos nuevos sentidos tienen que ver con la exigencia de que todo periodista en formación o en ejercicio fortalezca su competencia mediática, situación que avala la relevancia de un estudio como el que presenta este artículo

\section{Método e instrumento}

Fue el propio contexto investigativo, incipiente en la temática por abordar, el que determinó el tipo de estudio realizado. Tanto Colombia como Ecuador se decantaron por una investigación de corte exploratorio con evaluaciones descriptivas cuantitativas del nivel de competencia mediática de los periodistas. Ambos estudios tuvieron el mismo objetivo: realizar un primer análisis, detectar variables, relaciones y condiciones encontradas en las variables para describir más adelante las características más importantes del objeto de estudio específico (Hernández, Fernández \& Baptista, 2014).

En ambos países se aplicó un cuestionario autoadministrado, estructurado con nueve preguntas sociodemográficas, cuatro preguntas sobre las generalidades del nivel de competencia mediática y 24 evaluativas distribuidas en las seis dimensiones de este tipo de competencia, dimensiones que fueron operacionalizadas a partir de indicadores que fueron tomados del modelos de Ferrés y Piscitelli (2012) (Rivera, Zuluaga, Montoya \& Romero, 2017, p.83). Los indicadores se convirtieron en el cuestionario en preguntas cuyas opciones de respuesta fueron ponderadas y valoradas.

La mayoría de preguntas propuestas fueron cerradas con variables cualitativas y con posibilidades de respuesta de una sola opción, dicotómicas y politómicas; sin embargo, también se incluyeron preguntas cerradas con opción de múltiple respuesta y escalas de Likert (Hernández Sampieri et al., 2014).

\subsection{Procedimiento y consideraciones éticas}

En concordancia con el rigor metodológico, antes de la aplicación del instrumento de este estudio se hizo un proceso de adaptación y validación del cuestionario español que se estaba tomando como punto de referencia. La adaptación a los contextos latinoamericanos de este instrumento, pasó por las siguientes fases: revisión del cuestionario español, elaboración del primer cuestionario para el contexto latinoamericano; implementación de grupos de discusión con periodistas y expertos en cada una de dimensiones de la competencia mediática y redacción del cuestionario final. Mientras que en la validación se tuvo en cuenta un estudio piloto con 50 cuestionarios para evaluar la confiabilidad del instrumento con el coeficiente Alpha de Cronbach, que proporcionó un Alpha de 885 como resultado (Rivera, Zuluaga, Montoya \& Romero, 2017, p.84).

Se señala que el estudio tuvo en cuenta las debidas especificaciones éticas. Los periodistas encuestados fueron informados y consintieron participar al dejárseles en claro el tipo de instrumento que diligenciarían y la evaluación de la que serían objeto. Igualmente, se les explicó la utilización y acceso a los resultados del estudio, se les garantizó confidencialidad y por tratarse de una investigación no invasiva, sin impactos adversos para los participantes no requirió de la aprobación por un comité de ética. 
Para al análisis de datos, tanto en Colombia como en Ecuador, se estableció una escala valorativa que determinó las preguntas a calificar dentro del cuestionario y que igualó en peso cada una de las dimensiones $(16.66 \%)$ de la competencia mediática. En Colombia esta valoración del nivel de competencia se hizo por dimensiones desde los siguientes rangos valorativos: competencia alta ( $80 \%-100 \%)$, calificación 4.0-5.0; competencia media (60\%-79\%) calificación 3.0-3.9; competencia baja (40\%-59\%) calificación 2.0-2.9; competencia deficiente (0\%-39\%) calificación 0-1.9. En el caso ecuatoriano la valoración de competencias se hizo por pregunta y por dimensión según una escala de cero a 4 en la cual cero corresponde a la competencia deficiente, dos a la baja, tres a la mediana y 4 a la alta; pero los resultados conjuntos que presenta este artículo se ocupan de los datos generales arrojados por las dimensiones. A continuación se presenta, a modo de ejemplo, un apartado de la tabla de valoración:

Tabla 3. Valoración del cuestionario

\begin{tabular}{|c|c|c|c|c|}
\hline \multicolumn{5}{|c|}{ 1.DEFICIENTE } \\
\hline DIMEN. & ÁMB. & PREGUNTAS & RESPUESTAS & $\begin{array}{l}\text { VALORACIÓN DE CADA RES- } \\
\text { PUESTA }\end{array}$ \\
\hline & \multirow{9}{*}{$\frac{\frac{C D}{D}}{\frac{C}{1}}$} & \multirow{4}{*}{$\begin{array}{l}\text { 3.1. ¿Cuál de las siguien- } \\
\text { tes opciones describe } \\
\text { la manera como usted } \\
\text { realiza búsquedas en } \\
\text { Internet? (Señale una } \\
\text { sola casilla) }\end{array}$} & $\begin{array}{l}\text { Planifica la búsqueda teniendo en cuenta sus objetivos } \\
\text { y las herramientas disponibles, escoge los términos o } \\
\text { palabras clave, evitando ambigüedades; utiliza más de } \\
\text { una herramienta de búsqueda; y finalmente, compara } \\
\text { y evalúa la información hallada para seleccionar la que } \\
\text { más se adapte a sus objetivos. }\end{array}$ & 4 \\
\hline & & & $\begin{array}{l}\text { Decide dónde buscar, utilizando varios motores de } \\
\text { búsqueda y hace una indagación en profundidad (no } \\
\text { quedándose con los primeros resultados); evalúa las } \\
\text { respuestas: analizando quién creó el sitio, quién escribe } \\
\text { en él, fechas de actualización; comparando los resulta- } \\
\text { dos...; y finalmente, selecciona la respuesta que más } \\
\text { convenga a los objetivos de su trabajo. }\end{array}$ & 3 \\
\hline & & & $\begin{array}{l}\text { Escribe todas las palabras en un buscador del tipo Goo- } \\
\text { gle, ojea los primeros resultados que le ofrece el busca- } \\
\text { dor y selecciona el que considera más conveniente. }\end{array}$ & 2 \\
\hline & & & $\begin{array}{l}\text { Escribe todas las palabras en un buscador del tipo Goo- } \\
\text { gle y escoge la primera opción que se le ofrece. }\end{array}$ & 1 \\
\hline & & \multirow{5}{*}{$\begin{array}{l}\text { 3.2. ¿Qué palabras } \\
\text { escribiría en un busca- } \\
\text { dor como Google para } \\
\text { realizar la búsqueda de } \\
\text { las etapas literarias de } \\
\text { Gabriel García Márquez? } \\
\text { (Señale máximo dos } \\
\text { casillas) }\end{array}$} & \multirow{4}{*}{$\begin{array}{l}\text { Respuestas correctas: } \\
\text { Etapas AND/Y "Gabriel García Márquez". } \\
\text { "Las etapas literarias de Gabriel García Márquez" } \\
\text { Respuesta aceptable: } \\
\text { Etapas literarias AND/Y Gabriel García Márquez } \\
\text { Respuesta incorrectas: } \\
\text { Etapas literarias Gabriel García Márquez. } \\
\text { Obra Gabriel García Márquez. } \\
\text { Gabriel García Márquez Literatura }\end{array}$} & $\begin{array}{l}\text { Si señala las dos correctas } \\
4\end{array}$ \\
\hline & & & & $\begin{array}{l}\text { Si tiene } 1 \text { correcta y la aceptable } \\
3\end{array}$ \\
\hline & & & & $\begin{array}{l}\text { Si señala la aceptable y } 1 \text { de las } \\
\text { incorrectas es } \\
2\end{array}$ \\
\hline & & & & $\begin{array}{l}\text { Si señala cualquiera de las inco- } \\
\text { rrectas es } \\
1\end{array}$ \\
\hline & & & Otras ¿Cuáles?: & $\begin{array}{l}\text { Esta pregunta aportará puntos adi- } \\
\text { cionales y se definirá en la sistema- } \\
\text { tización que se entregará en Excel. }\end{array}$ \\
\hline \multirow{9}{*}{ 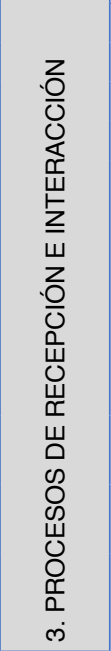 } & \multirow{9}{*}{ 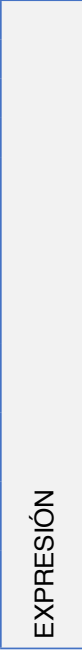 } & \multirow{4}{*}{$\begin{array}{l}\text { 3.3. ¿Se relaciona a } \\
\text { través de los medios } \\
\text { digitales con colegas? }\end{array}$} & No sabe & 1 \\
\hline & & & Nunca & 2 \\
\hline & & & A veces & 3 \\
\hline & & & Siempre & 4 \\
\hline & & $\begin{array}{l}\text { 3.4 Si la respuesta a la } \\
\text { pregunta anterior fue a } \\
\text { veces o siempre, especifi- } \\
\text { car cuál es la herramienta } \\
\text { digital que más utiliza } \\
\text { para esta comunicación: }\end{array}$ & \multicolumn{2}{|l|}{ NO SE VALORA ES INFORMATIVA } \\
\hline & & \multirow{4}{*}{$\begin{array}{l}\text { 3.5 Ha usado en alguna } \\
\text { ocasión los medios y tec- } \\
\text { nologías comunicativas } \\
\text { para realizar alguna de } \\
\text { las siguientes acciones } \\
\text { (puede marcar más de } \\
\text { una casilla): }\end{array}$} & \multirow{4}{*}{$\begin{array}{l}\text { Todas las respuestas son válidas a excepción de: } \\
\text { No he usado los medios y tecnologías comunicativas } \\
\text { para ninguna de estas acciones u otras similares. }\end{array}$} & $\begin{array}{l}\text { Si marca de } 8 \text { a } 9 \text { válidas } \\
4\end{array}$ \\
\hline & & & & $\begin{array}{l}\text { De } 7 \text { a } 5 \text { válidas: } \\
3\end{array}$ \\
\hline & & & & $\begin{array}{l}\text { De } 4 \text { a } 2 \text { válidas: } \\
2\end{array}$ \\
\hline & & & & $\begin{array}{l}1 \text { válida o la opción: No he usado } \\
\text { los medios...: } \\
1\end{array}$ \\
\hline
\end{tabular}

Fuente: Elaboración propia 
Por tratarse de un proceso evaluativo del nivel de competencia, la escala de valoración Alta, Media, Baja y Deficiente se caracteriza por los siguientes descriptores: quien obtiene una calificación ALTA, demuestra un desempeño con fortalezas en la mayoría de los indicadores que estructuran este nivel, pero no están excentos de mejoramiento. Para aquellos cuya calificación es MEDIA, el desempeño es básico y existe oportunidad de mejora en el 50\% de los indicadores de la competencia mediática. El nivel BAJO de competencia necesita refuerzo en la alfabetización mediática para fortalecer más del $50 \%$ de los indicadores de la competencia mediática y la DEFICIENTE el nivel de competencia es bajo en casi todos los indicadores y la formación para lograr un desempeño más eficaz en la interacción mediática debe ser más exhaustiva.

Finalmente, se deja en claro, que, por tratarse de un estudio cuantitativo basado en las variables de naturaleza cualitativa propuestas por Ferrés y Piscitelli (2012), la adaptación de los porcentajes iguales corresponde a seis dimensiones, integradas por 12 indicadores. Dimensiones que, por ser componente completo, son inseparables, indivisibles e iguales (Ferrés \& Piscitelli, 2012). También, se deja en claro que las discrepancias entre las diferentes evaluaciones / puntuaciones utilizadas entre Colombia y Ecuador no están en términos absolutos porque los resultados del presente estudio se presentan en términos de porcentaje de competencia y no por valores naturales (N) (Rivera, Zuluaga, Montoya \& Romero, 2017, p.84).

\subsection{Muestra}

Por tratarse de un estudio exploratorio se realizó frente al colectivo de periodistas un proceso de muestreo no probabilístico con el establecimiento de criterios preestablecidos que permitieran lograr representatividad frente al alcance de esta investigación: un primer acercamiento al objeto de estudio para realizar fases posteriores de mayor profundidad.

En Colombia se encuestaron 75 periodistas, $58.70 \%$ hombres y $38.60 \%$ mujeres $(2,7 \%$ no respondió esta pregunta) y en Ecuador 71, 79.10\% mujeres y $20.90 \%$ hombres. Esta muetra fue elegida por criterios específicos que le dieron heterogeneidad: en ambos países se trabajó con profesionales de diferentes medios de comunicación, públicos y privados; en Colombia participaron periodistas que habían integrado a su quehacer la relación comunicación-educación-medios y en Ecuador, por ejemplo, se incluyeron, periodistas de medios incautados por el Estado desde el 2008 para resarcir daños a la economía nacional por parte de sus dueños, grupo bancario que quebró en los años 90 .

\section{Resultados: Análisis y Discusión}

Los resultados que se describen en este artículo se consideran representativos porque es un estudio pionero que reúne información de 146 periodistas de diferentes medios, de dos países vecinos que comparten un similar contexto geográfico y social, al igual que un desarrollo parecido frente a los procesos teóricos e investigativos sobre la competencia mediática. Sin embargo, por tratarse de muestreos de una ciudad, por cada país, los resultados presentados son de la muestra y más que ser absolutos o generalizables, son valiosos para ambos países y, para el ámbito internacional, porque visualizan tendencias en torno al colectivo periodistas y al objeto de estudio abordado: la competencia mediática. Tendencias que por tratarse de una investigación precursora pueden servir de detonante para otros estudios, no solo nacionales, sino internacionales.

Los resultados se presentan, primero, por dimensiones y de manera comparativa entre ambos países el Gráfico 1, da cuenta de ello. Si se enfatiza en que, el ideal, sería obtener desempeños altos en todas las dimensiones, porque cada una de ellas es fundamental en la interacción mediática, aunque, el manejo de lo tecnológico y de los códigos lingüísticos de cada medio hayan sido vistos como los desempeños centrales en esta interacción. Sin embargo, el gráfico uno está lejos de los equilibrios, por ejemplo, en 
los hallazgos que devela el gráfico se resalta el mayor porcentaje de alta competencia, con un $64 \%$, de los periodistas colombianos en la dimensión Lenguaje. Esto significa que en el ámbito de la expresión y del análisis, los periodistas encuestados en Colombia, tienen habilidades y conocimientos para producir, interpretar mensajes a través de diferentes formas de representación, como la imagen y el sonido; pueden establecer relaciones entre textos y analizar, desde el significado y el sentido, estos diversos géneros y formatos. En Ecuador, la valoración que obtiene mayor porcentaje, con un 64\%, alta competencia es la dimensión Estética, lo cual significa que estos profesionales, demostraron fortalezas frente a la sensibilidad de reconocer y producir medios con un mínimo de calidad estética y artística. Y mientras que Colombia obtuvo un mayor porcentaje en la calificación Media y Baja competencia en la dimensión Estética. Ecuador en la dimensión Lenguaje, también ubicó mayor número de profesionales en la valoración Alta competencia; pero en menor grado que Colombia

Gráfico 1. Resultados generales de la competencia por dimensión RESULTADOS GENERALES DEL NIVEL DE COMPETENCIA POR DIMENSIÓN

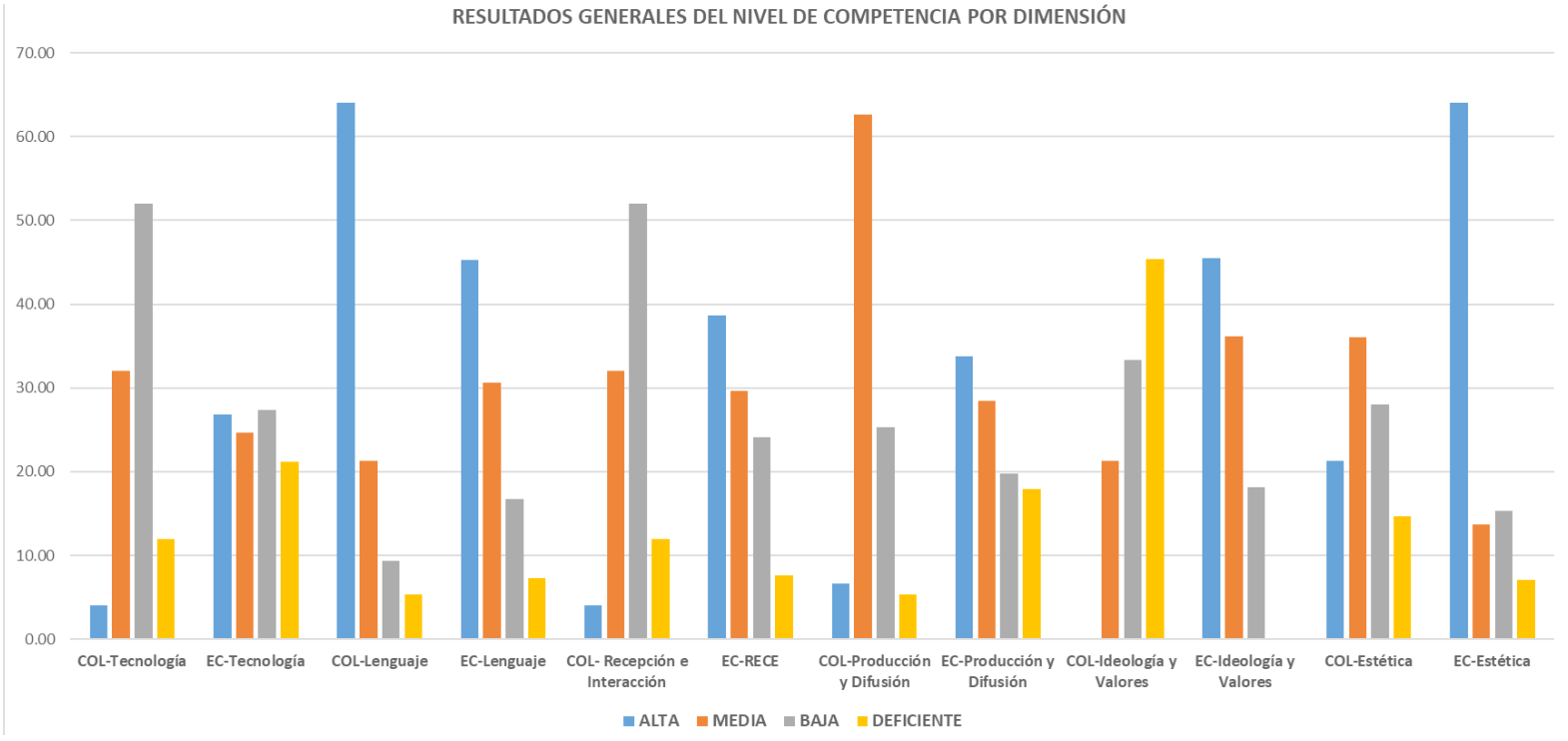

Fuente: Elaboración propia. Se indica que la abreviatura. COL, corresponde a Colombia y EC a Ecuador.

En el gráfico anterior también llama la atención la calificación de baja competencia en la dimensión Producción y Difusión de los periodistas colombianos. Y el hecho de que, aunque los periodistas ecuatorianos tienen mayor calificación en alta competencia, si se suman los porcentajes de baja y deficiente competencia, $37,76 \%$, esto supera a la calificación de alta competencia que fue, $33,75 \%$. Estas falencias detectadas no tienen que ver con los aspectos de producción y difusión clásicos de su formación profesional, sino en sus dificultades, por ejemplo, desde la expresión, para interactuar y producir nuevos significados de manera colaborativa en los actuales escenarios multimedia y multimodales; o falencias al manejar la propia identidad online/offline con actitud responsable ante el control de datos privados, propios o ajenos.

Igualmente, se resalta el desequilibrio entre los resultados de la dimensión Tecnología entre ambos países. En Colombia claramente, la tendencia es hacia una calificación de baja competencia entre los profesionales, con un 52\%; mientras que en Ecuador hay menos distancia entre todos los niveles valorativos, por ejemplo, la alta competencia y la baja tiene similares porcentajes. De manera clásica se supondría que este debería ser un nivel más fortalecido, por su instrumentalidad, pero los hallazgos no coinciden con esta concepción.

Ahora bien, en el Gráfico 2, se especifican los resultados por nivel de valoración entre ambos países. Al observar el gráfico se percibe un mayor equilibrio en las distribuciones de frecuencia en los ni- 
veles de valoración de media y baja competencia. Seguido por la deficiente. El mayor desequilibrio se presenta en el nivel de alta competencia.

Gráfico 2. Resultados por nivel valorativo

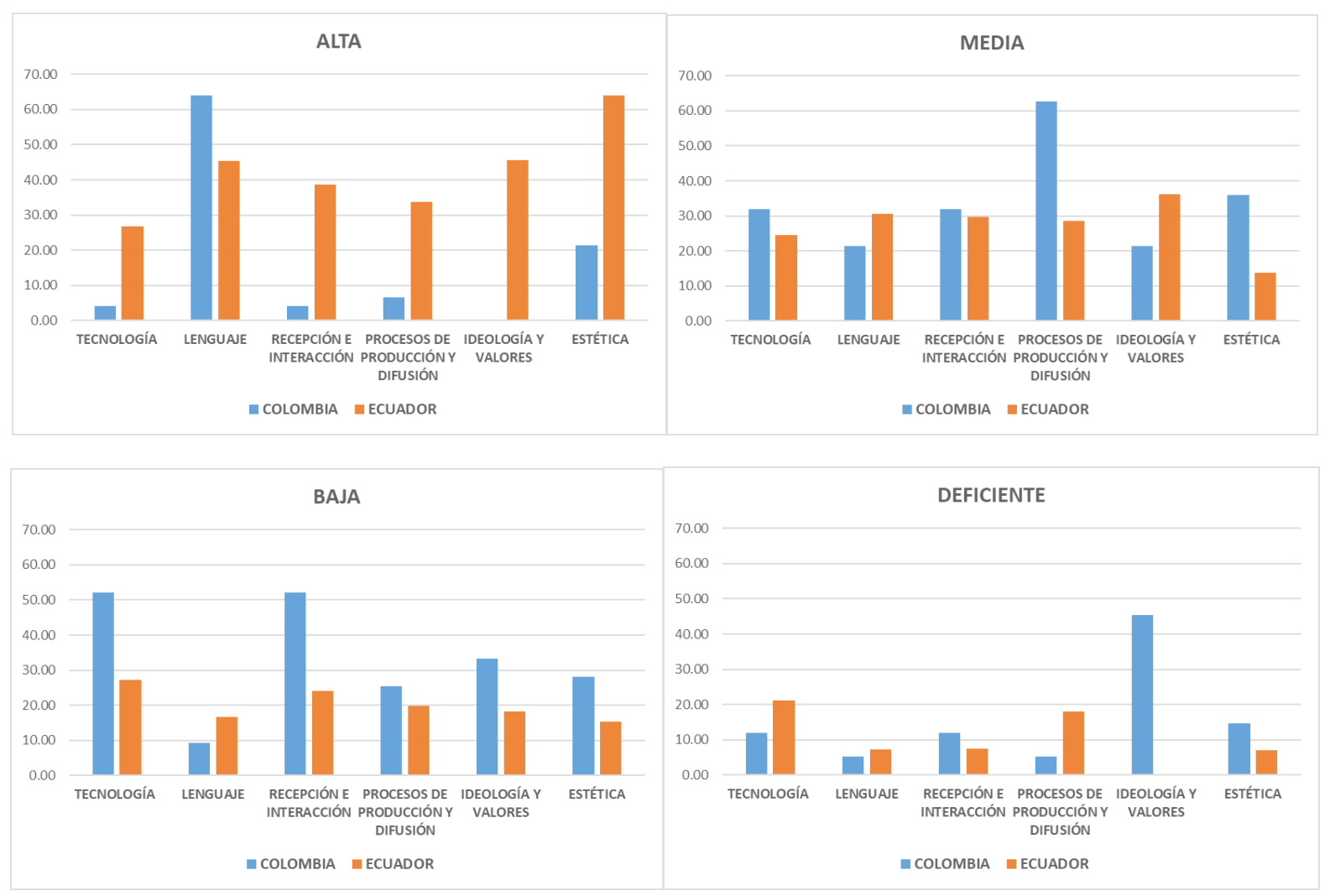

Fuente: Elaboración propia

Al revisar los resultados de la alta competencia, se evidencia que es Ecuador quien supera a Colombia en esta valoración en la mayoría de dimensiones a excepción de Lenguaje. Sin embargo, casi todos sus porcentajes están por debajo del $50 \%$, lo cual da cuenta de que en términos generales, no es el nivel de competencia más fuerte para ninguna de las dos naciones, y que cada dimensión está llamada a fortalecerse. Llama la atención la baja calificación en Tecnología, situación que puede relacionarse con el tipo de periodistas que participaron del estudio, por ejemplo el mayor rango poblacional se ubicó, con un 72.6\%, entre 41-50 y mayores de 50 años. El periodista de menor edad, tenía 22 años. Este tipo de población, no nació en contextos de alta Tecnología de la Comunicación e Información ni por su origen geográfico, ni por su edad.

Ecuador tiene la competencia de Ideología en más de $40 \%$ en nivel alto y en casi $40 \%$ en nivel medio. Y la competencia de Recepción en casi $40 \%$ en nivel alto y $30 \%$ en nivel medio. Mientras Colombia tiene la competencia de Ideología, en más de $85 \%$ en niveles bajo y deficiente. Y pasa lo mismo con la dimensión de Recepción. Más de $60 \%$ en niveles bajo y deficiente, esto quiere decir que un grueso número de periodistas de ambos países evidencia dificultades en el momento de consumir medios, como cualquier ciudadano común, a pesar de su formación profesional. Entre ellos, hay falencias a la hora de seleccionar con criterios conscientes y razonables su propia dieta mediática; les falta capacidad para dilucidar porque prefieren unos medios de otros o como sus emociones entran a interactuar con los consumos mediáticos que realizan; igualmente, quien tiene media o baja competencia mediática en la dimensión Recepción e Interacción enfrentará dificultades al interactuar con los medios para apoyar una construcción de ciudadanía que transforme el entorno social 
desde este ecosistema de múltiples pantallas. Igualmente, a los periodistas les falta solvencia en el momento de producir medios que aprovechen las innovaciones tecnológicas para promocionar valores que contribuyan a la mejora del entorno, desde una actitud de compromiso social y cultural.

Revisando el Gráfico 2 puede observarse que, en general, el nivel de competencia mediática de los periodistas que hicieron parte de este estudio se ubica entre la media y la baja competencia. Desempeños que los sitúan al mismo nivel de la población en general que ha sido valorada por las investigaciones reseñadas en el apartado de contexto de este manuscrito. Esto entra en contradicción con su responsabilidad social porque hacen parte de los grupos de producción de los medios y deja la siguiente interrogante ¿Cómo producir medios con calidad cuando no se cuenta con los suficientes conocimientos, habilidades y actitudes cuando se ocupa el lugar de consumidor mediático? Además, esta valoración general contradice la propia percepción de quienes fueron encuestados en el estudio.

También podría vincularse a este resultado el tipo de medios en el que laboran los periodistas, como lo evidencia el Gráfico 3.

La mayoría laboran en el área institucional, en prensa y en radio, que aún en épocas de convergencia, siguen en crisis frente a la integración de los nuevos ecosistemas comunicativos. Cómo puede apreciarse son menos los vinculados a medios nativos digitales.

Gráfico 3. Tipo de medio en el que laboran los periodistas

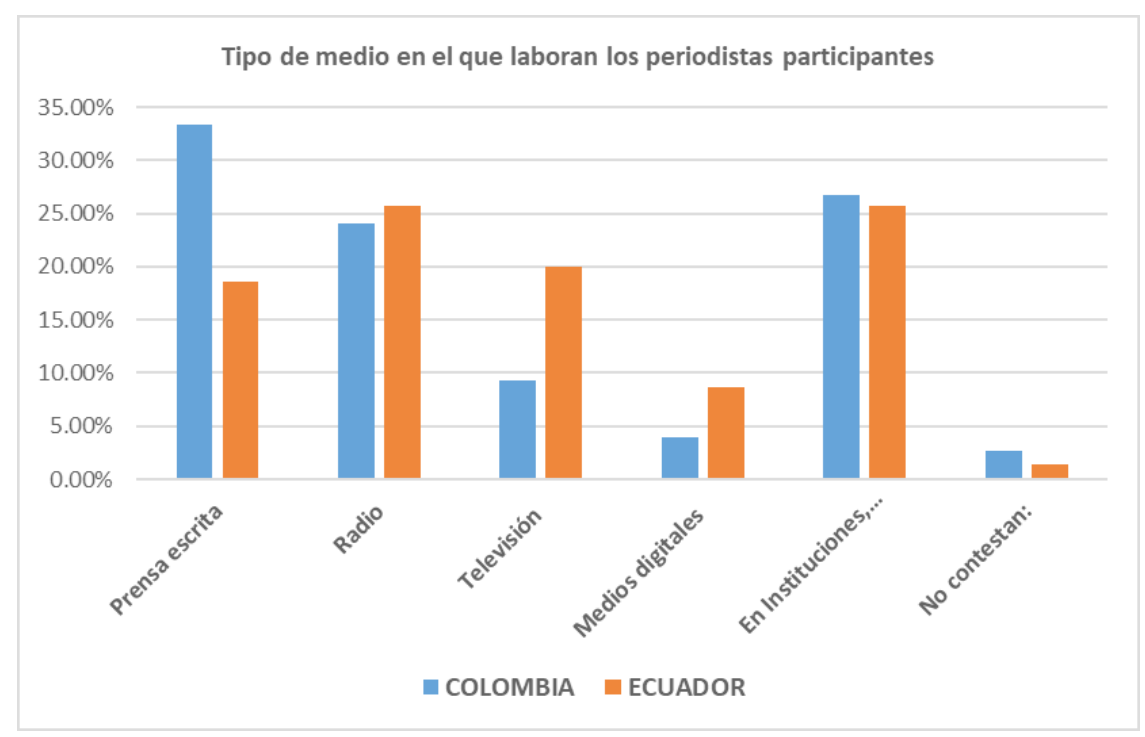

Fuente: Elaboración propia

El 38.6\% de las periodistas colombianas y el 79.1\% de las ecuatorianas; más el 58.7\% de los periodistas colombianos y el $20.9 \%$ de los ecuatorianos que fueron parte de este estudio respondieron, en las preguntas iniciales, antes de las de valoración, que su nivel de competencia mediática estaba entre los niveles alto y medio. Como se puede apreciar en el Gráfico 4, el mínimo de ellos se ubicó en los niveles de baja o ninguna competencia. Además, quienes obtuvieron más bajas valoraciones, los colombianos, fueron los de mayor frecuencia en el nivel de alta competencia. 
Gráfico 4. Percepción de los periodistas, sobre su nivel de competencia mediática

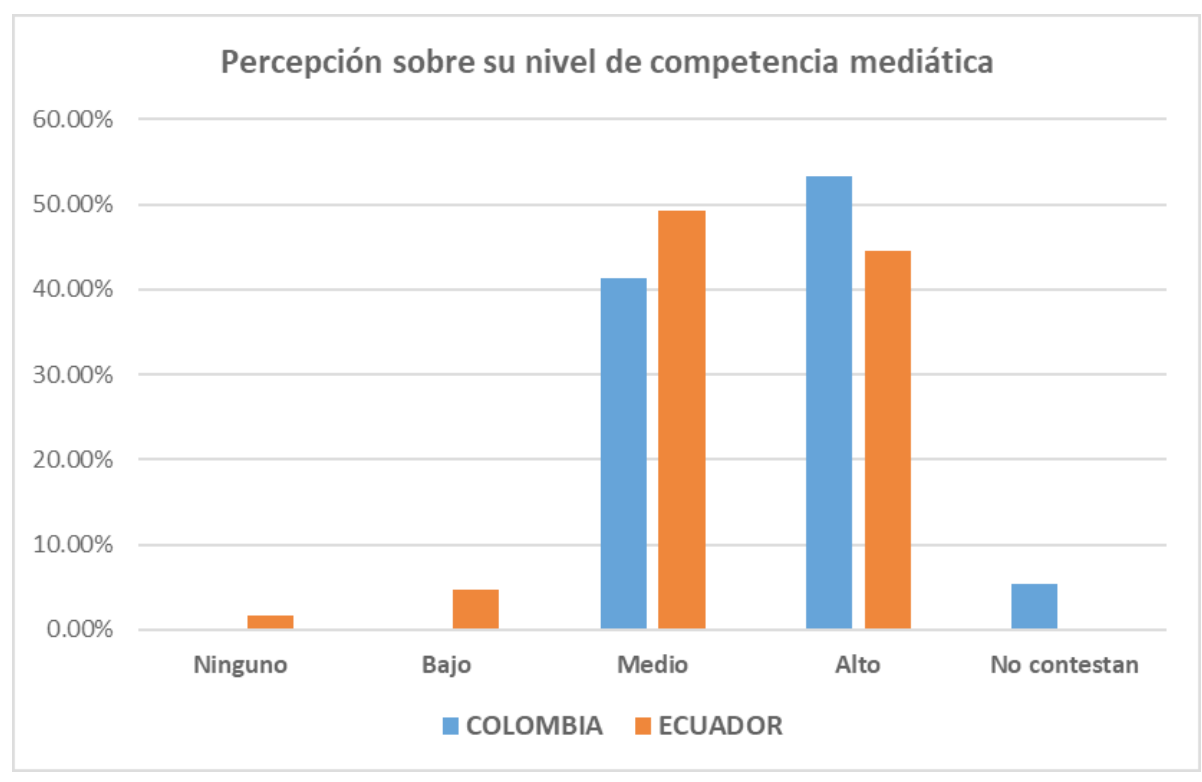

Fuente: Elaboración propia

Finalmente, frente a esta calificación y a esta percepción tan disonante preocupa el nivel de formación profesional de los periodistas encuestados. Si bien, no se puede garantizar que quien tiene una formación más avanzada sea más competente mediaticamente, por lo menos, podría acercarse a escenarios más complejos que le exijan este tipo de competencia. En ambos países, es mayor el número de profesionales sin posgrados $(74.6 \%$ en Colombia y el $76.6 \%$ en Ecuador) o formación de posgrado en proceso ( $73.3 \%$ en Colombia y $86.1 \%$ en Ecuador). En la población encuestada, en ambos países se puede evidenciar la carencia de formación superior a la profesionalización. Agrupando los datos de ambos países se evidenció que no hay formación doctoral entre los periodistas; maestrías solo el $19.6 \%$ y especializaciones el $22.5 \%$. Mientras que para la formación posgraduada en proceso solo se halló: un $4.6 \%$ de formación doctoral; un $16 \%$ en maestrías y un $5.3 \%$ en especializaciones.

\section{Conclusiones}

Los hallazgos que presenta este estudio cuestionan sobre un colectivo social poco analizado en torno a su competencia mediática, o sea, las actitudes y las habilidades cognitivas e instrumentales diversas que debe poseer un sujeto social en el momento de enfrentar sus diferentes roles dentro del ecosistema comunicativo, tanto de consumidor como de productor. Pareciera que los periodistas por su formación directamente relacionada con los medios de comunicación, se les considerara competentes mediáticamente per se; sin embargo, los resultados de esta investigación evidencian que en las dos ciudades del interior de Colombia y Ecuador estudiadas, los periodistas no alcanzaron la máxima calificación en todas las dimensiones de la competencia mediática y es más, cuando la obtuvieron, este valor porcentual siempre estuvo en los rangos de media y baja competencia.

Si este grupo social que debería, por su oficio, ser referente de altas competencias mediáticas, no lo logra, ¿qué podría esperarse de la ciudadanía en general si se tiene en cuenta la alta relevancia que debería tener el periodismo en la formación de las audiencias?

En esta evaluación general de competencia mediática, puede constatarse que hay un grupo de profesionales con mayores fortalezas en el manejo de la dimensión Lenguaje y la Estética dentro de lo mediático; sin embargo, hay debilidades en el uso de los nuevos artefactos tecnológicos; en el 
momento de producir y difundir a través de los medios pensando en el bien común y en la promoción de valores sociales; y en el reconocimiento de la propia identidad como consumidor mediático, razón por la cual faltan criterios entre los periodistas para evaluar su dieta mediática o para analizar críticamente los efectos que sus actuaciones generan en sus públicos.

Debe señalarse que hay diferencias entre las calificaciones de los periodistas colombianos y ecuatorianos. Estos últimos obtuvieron mejores calificaciones, lo cual es coherente con lo enunciado en el apartado, Contexto Investigativo, de este manuscrito en el cuál se indica que a diferencia de los colombianos, los periodistas ecuatorianos valoran más sus procesos formativos y el oficio del periodismo. No obstante, sí se esperarían mejores resultados de este colectivo social porque las últimas investigaciones internacionales (España, 2011-2017: Red Alfamed, Red Interuniversitaria Euroamericana de Investigación de Competencias Mediáticas para la Ciudadanía, 2015-2017) que han evaluado competencia mediática para la ciudadanía en general han arrojado valoraciones entre media y baja competencia, muy a la par con los periodistas que fueron encuestados en esta investigación.

Los datos que evidencia esta investigación invitan a discusiones sobre el rol del periodismo actual y la formación de quienes lo ejercen. Periodismo que puede plantearse en crisis desde los abordajes tradicionales. En palabras de Rincón (2017).

El siglo XX terminó en 2016: en política, murió Fidel Castro; en periodismo, no logró contar el mundo. La gran ruina que vive el periodismo es que ha dejado de narrar la democracia, de hacer sentido de nuestra contemporaneidad, de contar las realidades de la gente común, de controlar al poder. Así, el oficio periodístico es una especie en vías de extinción en los grandes medios de referencia que han decidido convertirse en actores políticos que hacen lobby para intereses empresariales y han convertido a la información en sensacionalismo o farándula. Así, hemos llegado a un mundo donde el valor de la información periodística es bajo y la legitimidad y credibilidad mediática está arruinada (p.17).

La urgencia es resignificar el ejercicio del periodismo y reinventar sus decires y haceres. Tal vez desde esta lógica pueda hablarse de profesionales que puedan convertirse en referentes para la ciudadanía en general, porque como puente entre los medios y los sujetos sociales, los periodistas están obligados a demostrar altas competencias, en muchos aspectos; pero, sobre todo, en aquellas que como la mediática dan cuenta de una interacción y una producción mediática asertiva, crítica y pensada en un desarrollo social que beneficie a todos los colectivos sociales.

\section{Agradecimiento}

La investigación de este artículo se basa en el proyecto I+D «Competencia mediática en un entorno digital. Diagnóstico de necesidades en tres ámbitos sociales», de referencia EDU201021395-C03-01.

\section{Bibliografía}

Alberdi, A., Armentia, A., Armentia Vizuete, J. I., Caminos Marcet, JM. y Marín Murillo, F. (2003). La remodelación de El Periódico de Catalunya: hacia el modelo de prensa de servicios. Ámbitos, 9(10), 275-300.

Barbero, J.M. (2003). Saberes hoy: diseminaciones, competencias y transversalidades. Revista Iberoamericana de Educación. 32, 17-34. http://goo.gl/LlkMRT

Buitrago, A., Ferrés, J., y García Matilla, A. (2015). La educación en competencia mediática en el CV de los periodistas. Index-comunicación, 5 (2), 101-120. 
Campos Freire, F. (2010). Los nuevos modelos de gestión. de las empresas mediáticas. Revista Estudios sobre el Mensaje Periodístico,16.

Cárdenas, M. (2016). Formación periodística: Una mirada a las nuevas generaciones del periodismo radial en Villavicencio (Doctoral dissertation). Corporación Universitaria Minuto de Dios.

Cebrián Echarri, B. (2015). Propuestas para mejorar la formación de los periodistas en el siglo XXI. Index-comunicación, 5 (2).

Ferrés, J. \& Piscitelli, A. (2012). La competencia mediática: propuesta articulada de dimensiones e indicadores. Comunicar, 19 (38), 75-82. http://dx.doi.org/10.3916/C38-2012-02-08

Gómez Nieto, B. (2017). La función educadora de la prensa como mass media en la era digital. Estudios sobre el Mensaje Periodístico, 23(1), 45-60. https://tinyurl.com/yxtsdq4y

Gutiérrez Martín, A., y Tyner, K. (2012). Educación para los medios, alfabetización mediática y competencia digital. Comunicar, 19(38), 31-39. https://doi.org/10.3916/C38-2012-02-03

Gutiérrez Atala, F., Domínguez Panamá, J., Odriozola Chné, J. y Ferreira Jiménez, J. (2017). Limitantes Formativas en la praxis profesional: estudio de la situación de periodistas en Chile, México, Ecuador y Colombia. Comuni@cción, 8 (1).

Hernández Sampieri, R., Fernández Collado C. y Baptista Lucio, M. P. (2014). Metodología de la Investigación. Mcgraw-Hill.

Huergo, J. (2010). Una guía de comunicación/educación, por las diagonales de la cultura y la política. En Aparici, R (Ed.), Educomunicación: más allá del 2.0. (pp. 65-104). https://goo.gl/ $\mathrm{XBqGr} 5$

Kendall, A., \& Mcdougall, J. (2012). Alfabetización mediática crítica en la postmodernidad. Comunicar, 19(38), 21-29. https://doi.org/10.3916/C38-2012-02-02

Langa-Nuño, C. (2010). Claves de la historia del periodismo. En La dinámica periodística: perspectiva, contexto, métodos y técnicas / coord. Ramón Reig. Asociación Universitaria Comunicación y Cultura (AUCC) y Grupo de Investigación en Estructura, Historia y Contenidos de la Comunicación (GREHCCO) de la Universidad de Sevilla.

Lavín De Las Heras, E. (2015). Los hitos que marcaron el inicio del periodismo ciudadano. http:// www.cuadernosartesanos.org/\#85

Manrique-Grisales, J., Sandoval Romero, Y. y Arenas Fernández, A. (2017). Competencia mediática en Colombia: marcos de referencia para un diagnóstico. Nexus Comunicación. $\mathrm{N}^{\circ} 21$. enero - junio de 2017.

Montoya Ramírez, N. M., y Zuluaga Arias, L. I. (2014). Educar mientras se informa: Una propuesta de resignificación de la prensa tradicional. Signo y Pensamiento, 33(64), 30-44. https:// doi.org 10.11144/Javeriana.SyP33-64.emsi

Montoya Ramírez, N. M., y Zuluaga Arias, L. I. (2017). La formación en competencias mediáticas de estudiantes de educación básica: una experiencia educomunicativa y ciudadana que reconfigura el papel de la prensa escrita. En Actas del Tercer Congreso Internacional de Educación Mediática y Competencia Digital. 15, 16 y 17 de junio. Campus María Zambrano de Segovia. Universidad de Valladolid - España. 
Orozco, G. (1997). Medios, audiencias y mediaciones. Comunicar, 8, 25-30.

Pérez Tornero, J.M., \& Varis, T. (2012). Alfabetización mediática y nuevo humanismo Colección: Media Literacy, 2. Universitat Oberta de Catalunya

Raigón Pérez De La Concha, G. (1998). El periodismo educativo: objetivos. Sevilla: Universidad de Sevilla, España. http:// grupo.us.es/grehcco/ambitos01/01raigon.pdf

Rincón, O. (2010). ¿Por qué nos odian tanto? Estado y medios de comunicación en América Latina. Bogotá, Colombia: Centro de Competencia en Comunicación para América Latina. https:// goo.gl/dZ5kC7

Rincón, O. (2017). Periodismo mutante y bastardo. Revista CS, 22, 15-31. http://dx.doi. org/10.18046/recs.i22.2394

Rivera-Rogel, D., Zuluaga Arias, L., Montoya Ramírez, N. \& Rodríguez, L. (2017). Media Competencies for the Citizenship Training of Teachers from Andean America: Colombia and Ecuador. Paidéia, 27 (66), 80-89. http://dx.doi.org/10.1590/1982-43272766201710.

Romero-Rodríguez, L.M., \& Aguaded, I. (2016). Consumo informativo y competencias digitales de estudiantes de periodismo de Colombia, Perú y Venezuela. Convergencia, 23(70), 35-57. https://bit.ly/2QPECxZ

Scolari, C. (2013). Narrativas transmedia: cuando todos los medios cuentan. Deusto.

Tucho, F., Fernández-Planells, A., Lozano, M., y Figueras-Maz, M. (2015). La educación mediática, una asignatura pendiente en la formación de periodistas, publicitarios y comunicadores audiovisuales. Revista Latina de Comunicación Social, (70), 689-702. https://www.redalyc.org/ articulo.oa?id=819/81948469036

Zambrano Ayala, W. R., García Ramírez, D., Barrios Rubio, A. (2019). El periodista frente a los nuevos retos y escenarios de la convergencia mediática en Colombia. Estudios sobre el Mensaje Periodístico. 25(1) 587-607. http://dx.doi.org/10.5209/ESMP.63747 